\title{
The Effects of Gamification on Restaurant \\ Consumer-Retention
}

\author{
Kyra L. Harakal \\ Bentley University, Waltham, MA 02452, USA \\ Paul D. Berger (Corresponding author) \\ Bentley University, Waltham, MA 02452, USA \\ Tel: 617-974-5888Ｅ-mail: pberger@bentley.edu
}

Received: January 22, 2017 Accepted: February 27, 2017

doi:10.5296/ber.v7i1.10634 URL: https://doi.org/10.5296/ber.v7i1.10634

\begin{abstract}
This paper considers the marketing concept of gamification. This includes most loyalty programs, but, in addition, has tentacles in many other areas of marketing. It is a concept which has been growing rapidly in the marketing field. While a lot has been written about it, there is little quantitative analysis of its impact. In this paper, we perform a statistical analysis using a database of about 1,100 people and several variables, related to the restaurant industry in particular. We consider several hypotheses. One is whether the consumer loyalty engendered by gamification differs by gender. Another is the relationship between customer loyalty engendered by gamification and some restaurant-specific measures, such as frequency of visits to the restaurant, amount of money spent at a restaurant, and the impact of special rewards programs. We also consider which variables are significant in a predictive model with the dependent variable: I would visit a restaurant more often with the presence of as points-based reward program, and several of the earlier-considered variables as independent variables.
\end{abstract}

Keywords: Gamification, Restaurant data, Reward programs, Stepwise regression

\section{Introduction}

What do Snapchat, Nike+, and the Starbucks Rewards app have in common? Beside the fact that each of these can be conveniently downloaded and used on a mobile phone, they each implement a very similar strategy in order to increase consumer retention. All three use a system of points, trophies, badges, or challenges to encourage higher usage and loyalty.

- Snapchat's users receive trophies after taking specific pictures, in turn increasing app usage. 
- Nike+ encourages individuals to live a healthier life by setting challenges and rewarding the completion of these objectives with points and badges.

- After buying a caramel macchiato through the Starbucks App, a consumer receives points toward a free drink, thereby encouraging customer loyalty.

This very effective strategy is gaining exponential traction within the marketing industry and is effectively known as gamification. While there is a plethora of literature on the theoretical implications of gamification, there have been few quantitative studies of this topic and its relationship to consumer loyalty across demographics. In this paper, we explore gamification and present our findings on the effect of a gamified rewards-programs on consumer loyalty via a statistical analysis of data that is part of a 2014 survey on restaurant consumer-loyalty. In the first part of the paper, we further discuss the theory of gamification and its relation to marketing and customer loyalty programs. In the second part, we propose research questions and provide discussion of our methodology, explaining how the data used in this paper was collected and analyzed. In the third section, we investigate our findings and present our conclusions. Lastly, the fourth section addresses potential limitations to our study and directions for future research.

\section{Literature Review}

\subsection{Theory of Gamification}

The origins of gamification can be found within the marketing industry in 2003 (Seaborn \& Fels, 2014). However, over the past decade, gamification has grown rapidly and has spread throughout almost every field, including education, manufacturing, retail, food services, and health care. In fact, the global market for gamification is anticipated to reach $\$ 5.5$ billion by 2018 (Esteves, 2015) and $\$ 11.1$ billion by 2020 (Tiwari, 2016), an increase from $\$ 421$ million in 2013 (Esteves, 2015) and $\$ 1.7$ billion in 2015 (Tiwari, 2016). As a result of its widespread presence, the definition of gamification has not been $100 \%$ agreed upon by scholars. Nevertheless, within the context of this paper we define gamification using Deterding's and Hamari's definition - "the use of game elements in non-game contexts," (Hamari, 2013).

While the definitional classification of gamification has been widely disputed, scholars have agreed upon a standard set of "game elements" - badges, points, challenges, levels, leaderboards, etc. - to be used within a gamified system in order to make products and services more appealing and fun. For consumers, gamification allows for better engagement with purchases, increases value creation, enhances services, and builds a relationship between buyer and supplier. With respect to businesses and providers/sellers, gamification entices future buys, attracts customers, and provides data for customer segmentation.

\subsection{Gamification in Marketing}

Within the field of marketing, Hamari, Huotari, and Tolvanen (2014) have recognized four areas in which gamification can be implemented - transactional marketing, relationship marketing, service marketing, and experiential marketing. In transactional marketing, gamification can be used to maximize individual sales without necessarily forming a relationship between consumer and supplier (Rouse, 2009). Conversely, relationship 
marketing uses gamification to form long-term relationships between buyer and seller, while service marketing uses gamification in order to "enhance" a service for individuals (Hamari et al., 2014). Experiential marketing implements gamification as a means to completely immerse consumers in the evolution of a product or service (Moth, 2014). The use of gamification in these four areas of marketing has become so prevalent that $87 \%$ of retailers plan to use gamification as a way to increase consumer engagement within the next five years (Egan, 2015).

\subsection{Gamification in Loyalty Programs}

While there are several gamification strategies that businesses can implement to increase consumer engagement and drive revenues, the rest of this paper focuses on a specific strategy of doing so: loyalty programs. Investopedia defines a loyalty program as a "rewards program offered by a company to customers who frequently make purchases," (Investopedia.com, 2016). These programs may offer discounted coupons, points, early access, special services, etc., to their users in order to drive loyalty and, in turn, sales. However, not every loyalty program can be classified as gamification. Specifically, a gamified loyalty program would have to implement at least one or more of the previously mentioned gaming elements. We now focus exclusively on loyalty programs that offer points, levels, and/or challenges.

\section{Methodology}

As noted earlier, gamification's presence within the marketing industry appears to be growing rapidly, and yet, few statistical studies have been done regarding its effect on consumer loyalty. It is possible that the lack of in-depth analysis is due to the unquantifiable nature of gamification. In fact, Conaway and Garay (2014) go as far to state that "to date no published instruments or surveys appear in the indexed scientific literature that addresses or quantifies gamification." As a result, the process of collecting data for analysis proved to be particularly difficult and it was ultimately decided that a portion of Loyalogy's 2014 survey results on restaurant customer-loyalty would be used for our analysis (Duffy, 2014). The decision to use a previously collected dataset was twofold. First, Loyalogy's dataset, consisting of 1,100 viable respondents, was far larger than any data that could have been collected independently within the authors' budget and timeframe. Second, with over 130 total variables, Loyalogy's survey provides the largest available dataset on customer loyalty available to the general public. Given both of these factors, Loyalogy's survey data provided the most accurate potential dataset for exploring the relationship between gamified loyalty programs and potential customer retention. The final dataset had a population size of $n=1,100$ and 132 potential variables to investigate. Given this information, the following research questions are proposed:

- Q1: What are the overall demographic statistics within the survey?

- Q2: Does consumer loyalty as a result of gamification differ by gender?

- Q3: What is the relationship between customer loyalty and

a) total visits to restaurants per month,

b) total spending per restaurant visit, 
c) total number of dining rewards-programs per person during the year,

d) total spending in retail throughout the year, and

e) total rewards programs during the year (not only restaurants)?

- Q4: Which variables will "survive" in a predictive model produced through application of the stepwise-regression process, with a dependent variable of, "I would visit a restaurant more often with the presence of a points-based reward program?"

\section{Analysis and Discussion of Results}

\subsection{Demographic Comparisons}

A descriptive analysis was performed using SPSS on the following seven variables: "I would visit a restaurant more if a points-based rewards program was present" (using a 5-point scale, where 1 = strongly disagree, 5 = strongly agree); "I would recommend a restaurant more if a points-based rewards program was present" (using a 5-point scale, where 1 = strongly disagree, 5 = strongly agree); "Total visits to restaurants per month [on average during the past year]" (actual number); "Total spending per visit to a restaurant [on average during the past year]" (U.S. dollars); "Total number of memberships in dining rewards programs" [during the past year] (actual number); "Total spending in retail during the past year" (U.S. dollars); "Total Number of Memberships in Rewards Programs" [during the past year] (actual number - not only restaurants). This analysis produced Figure 1:

\begin{tabular}{|c|c|c|c|c|c|}
\hline & \multicolumn{5}{|c|}{ Descriptive Statistics } \\
\hline & $N$ & Minimum & Maximum & Mean & Std. Deviation \\
\hline $\begin{array}{l}\text { Iwouldvisitthatrestaurant } \\
\text { moreoften. } \\
\text { Ifarestaurantyouli }\end{array}$ & 1100 & 1 & 5 & 4.09 & .986 \\
\hline $\begin{array}{l}\text { Iwouldrecommendthatres } \\
\text { taurantmoreoftentopeopl } \\
\text { elknow.I }\end{array}$ & 1100 & 1 & 5 & 4.02 & 1.028 \\
\hline Totalvisitstorestaurants & 1100 & 0 & 120 & 12.88 & 17.138 \\
\hline Totalspendingpervisit & 1100 & 0 & 900 & 97.60 & 85.154 \\
\hline $\begin{array}{l}\text { Totaldiningrewardsprogr } \\
\text { ams }\end{array}$ & 1100 & 0 & 100 & 3.01 & 9.974 \\
\hline TotalSpendinginretail & 1100 & 0 & 112250 & 6232.19 & 7940.487 \\
\hline TotalRewardsprograms & 1100 & 0 & 300 & 8.10 & 23.386 \\
\hline Valid N (listwise) & 1100 & & & & \\
\hline
\end{tabular}

Figure 1. Descriptive statistics for 7 key quantities

As can be seen from Figure 1, on a scale from 1-5, the mean responses to "I would visit a restaurant more if a points-based rewards program was present" and "I would recommend a restaurant more if a points-based rewards program was present" were 4.02 and 4.09, respectively, averaged over the 1,100 respondents. With " 4 " representing "Agree" and "5" representing "Strongly Agree," it appears that the presence of a points-based loyalty program does have a substantial impact on an individuals' loyalty to an establishment. Regarding "Total visits to restaurants per month" it was found that the mean number of visits per month 
was 12.88. This number is somewhat variable among the respondents, with a minimum of 0 (there were only a few of these), and a maximum of 120, the latter value, presumably, if not a typo in the data set, representing a not-so frequently-occurring person who eats every meal in a restaurant, 4 meals per day for 30 days. The average amount spent per restaurant visit spending averaged $\$ 97.60$; this value also varied somewhat, although the mean is slightly understated, since the "\$0 spending" does not really represent an average amount spent per visit, but, rather, reflects those few instances when a responder did not visit a restaurant at all during the year. While, in an ideal case, an adjustment should be made based on this, we do not believe that the degree of "understatement" is material. We are a bit surprised with the maximum value of $\$ 900$, and wonder if it is correct (or, again, a typo in the data set;) however, that one response did not materially affect the average value across the sample size of 1,100 . The average number of dining rewards-programs per person was 3.01 , while the mean total number of rewards program per person was 8.10. Lastly, the mean total spending in retail throughout the year for the 1,100 responders was $\$ 6,232.19$ per year.

As we will note in our limitations section, an analysis to seek out and eliminate "outliers" was not performed.

\subsection{Independent Samples T-Test on Gender}

An independent samples t-test was performed on SPSS using the test variable of "I would visit a restaurant more if a points-based rewards program was present" and using the grouping variable of "Gender," the results of which can be found in Figure 2.

\begin{tabular}{ll|r|r|r|r} 
& \multicolumn{3}{c}{ Group Statistics } & & \\
& Whatisyourgender & $N$ & Mean & Std. Deviation & $\begin{array}{c}\text { Std. Error } \\
\text { Mean }\end{array}$ \\
\hline $\begin{array}{l}\text { Iwouldvisithatrestaurant } \\
\text { moreoften. } \\
\text { lfarestaurantyouli }\end{array}$ & Female & 715 & 4.17 & .963 & .036 \\
\cline { 2 - 7 } & Male & 385 & 3.95 & 1.014 & .052 \\
\hline
\end{tabular}

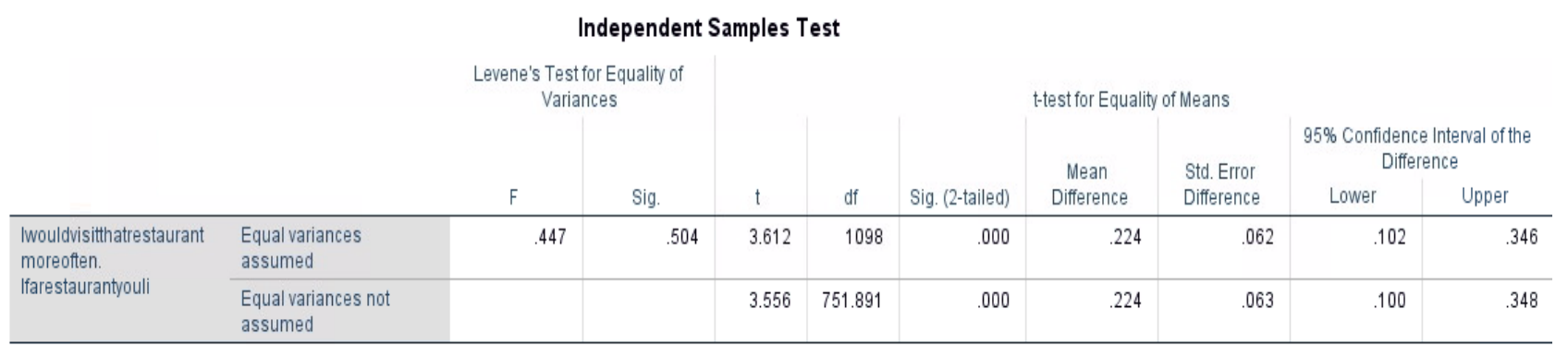

Figure 2. T-test results for independent t-test analysis using SPSS

As can be seen in the top section of Figure 2, the mean response for females was 4.17 and the mean response for males was 3.95. Using a traditional value of $\alpha=.05$, these results are highly significant, with a p-value of .000 (examining the "Sig. (2-tailed)" [p-value, as labeled by SPSS] column, rounded to 3 digits), as seen in that respective column in the bottom section of the output, about in the middle. In this case, it makes no difference, but the Levene test result (first section, 3 columns, in the bottom section of output) indicates an acceptance 


\section{Macrothink}

Business and Economic Research

ISSN 2162-4860

2017, Vol. 7, No. 1

of the hypothesis that the variance is the same for the two genders ( $p$-value $=.504>.05$ ), and, consequently, the top of the two ".000" p-values is the appropriate one to use. Hence, we conclude, beyond a reasonable doubt, that females are more inclined than males to embrace customer loyalty, based on a points-based reward system.

\subsection{Multiple Regression Analysis}

Next, a multiple linear-regression analysis was conducted using SPSS on the relationship between the dependent variable: A person would visit a restaurant more often with the presence of a points-based rewards program and 5 independent variables:

- "Total visits to restaurants per month

- "Total spending per restaurant visit,"

- "Total dining rewards programs,"

- "Total spending in retail per year," and

- "Total rewards programs.

Results are shown in Figure 3:

Model Summary

\begin{tabular}{ll|r|r|r} 
Model & $\mathrm{R}$ & R Square & \multicolumn{1}{c}{$\begin{array}{c}\text { Adjusted R } \\
\text { Square }\end{array}$} & $\begin{array}{c}\text { Std. Error of } \\
\text { the Estimate }\end{array}$ \\
\hline 1 & $.176^{\mathrm{a}}$ & .031 & .026 & .973 \\
\hline
\end{tabular}

a. Predictors: (Constant), TotalRewardsprograms,

Totalspendingpervisit, TotalSpendinginretail,

Totalvisitstorestaurants, Totaldiningrewardsprograms

\begin{tabular}{|c|c|c|c|c|c|c|}
\hline \multicolumn{7}{|c|}{ ANOVA $^{a}$} \\
\hline Model & & $\begin{array}{l}\text { Sum of } \\
\text { Squares }\end{array}$ & df & Mean Square & $\mathrm{F}$ & Sig. \\
\hline \multirow[t]{3}{*}{1} & Regression & 33.039 & 5 & 6.608 & 6.976 & $.000^{\mathrm{b}}$ \\
\hline & Residual & 1036.316 & 1094 & .947 & & \\
\hline & Total & 1069.355 & 1099 & & & \\
\hline
\end{tabular}

a. Dependent Variable: Iwouldvisitthatrestaurantmoreoften. Ifarestaurantyouli

b. Predictors: (Constant), TotaIRewardsprograms, Totalspendingpervisit,

TotalSpendinginretail, Totalvisitstorestaurants, Totaldiningrewardsprograms 


\begin{tabular}{|c|c|c|c|c|c|c|}
\hline \multicolumn{7}{|c|}{ Coefficients $^{a}$} \\
\hline \multirow[b]{2}{*}{ Model } & & \multicolumn{2}{|c|}{ Unstandardized Coefficients } & \multirow{2}{*}{$\begin{array}{c}\text { Standardized } \\
\text { Coefficients } \\
\text { Beta }\end{array}$} & \multirow[b]{2}{*}{$t$} & \multirow[b]{2}{*}{ Sig. } \\
\hline & & $\mathrm{B}$ & Std. Error & & & \\
\hline \multirow[t]{6}{*}{1} & (Constant) & 3.906 & .050 & & 77.637 & .000 \\
\hline & Totalvisitstorestaurants & .006 & .002 & .107 & 3.069 & .002 \\
\hline & Totalspendingpervisit & .001 & .000 & .129 & 4.181 & .000 \\
\hline & $\begin{array}{l}\text { Totaldiningrewardsprogr } \\
\text { ams }\end{array}$ & .001 & .004 & .014 & .328 & .743 \\
\hline & TotalSpendinginretail & $-6.734 \mathrm{E}-6$ & .000 & -.054 & -1.745 & .081 \\
\hline & TotalRewardsprograms & $-6.290 \mathrm{E}-5$ & .002 & -.001 & -.038 & .970 \\
\hline
\end{tabular}

a. Dependent Variable: Iwouldvisitthatrestaurantmoreoften.Ifarestaurantyouli

Figure 3. Results of multiple regression

Only two of the 5 independent variables are significant (using $\alpha=.05$ ): "Total visits to restaurants per month" $(\mathrm{p}=.002)$ and "Total spending per restaurant visit" $(\mathrm{p}=.000$, rounded to 3 digits). "Total spending in retail per year" was close to significant $(\mathrm{p}=.081)$, while "Total dining rewards programs" $(p=.7430)$ and "Total rewards programs" $(p=.970)$ were not (even close to) significant in determining the dependent variable. Furthermore, the overall fit of the multiple linear- regression was on the low side, with an R-square of 0.031 . In other words, we estimate that only $3.1 \%$ of the variability in whether an individual would visit a restaurant more often with the presence of a points-based rewards program can be explained by the set of 5 independent variables. However, the results did show that the two significant variables, "Total visits to restaurants per month" and "Total spending per visit to restaurant," were positively related to customer loyalty, a result that would appear to be directionally correct.

\subsection{Stepwise Regression}

Lastly, a stepwise regression was performed on SPSS using the dependent variable "I would visit a restaurant more often if a points-based loyalty program was present" with the same 5 independent variables. This was a logical next step, for, with 3 non-significant variables showing up in Figure 3, it is possible that there is some co-linearity among the three. A stepwise regression might possibly reveal this, and, in any case, will reveal the "best" predictive model. The results of the stepwise regression are shown in Figure 4.

\section{Model Summary}

\begin{tabular}{|c|c|c|c|c|}
\hline Model & $\mathrm{R}$ & R Square & $\begin{array}{c}\text { Adjusted R } \\
\text { Square }\end{array}$ & $\begin{array}{l}\text { Std. Error of } \\
\text { the Estimate }\end{array}$ \\
\hline 1 & $.128^{a}$ & .016 & .015 & .979 \\
\hline 2 & $.167^{b}$ & .028 & .026 & .973 \\
\hline
\end{tabular}




\begin{tabular}{|c|c|c|c|c|c|c|}
\hline \multicolumn{7}{|c|}{ ANOVA $^{a}$} \\
\hline Model & & $\begin{array}{l}\text { Sum of } \\
\text { Squares }\end{array}$ & df & Mean Square & $\mathrm{F}$ & Sig. \\
\hline \multirow[t]{3}{*}{1} & Regression & 17.397 & 1 & 17.397 & 18.158 & $.000^{\mathrm{b}}$ \\
\hline & Residual & 1051.958 & 1098 & .958 & & \\
\hline & Total & 1069.355 & 1099 & & & \\
\hline \multirow[t]{3}{*}{2} & Regression & 29.891 & 2 & 14.945 & 15.773 & $.000^{\mathrm{c}}$ \\
\hline & Residual & 1039.465 & 1097 & .948 & & \\
\hline & Total & 1069.355 & 1099 & & & \\
\hline
\end{tabular}

\begin{tabular}{|c|c|c|c|c|c|c|}
\hline \multicolumn{7}{|c|}{ Coefficients $^{a}$} \\
\hline \multirow[b]{2}{*}{ Model } & & \multicolumn{2}{|c|}{ Unstandardized Coefficients } & \multirow{2}{*}{$\begin{array}{c}\text { Standardized } \\
\text { Coefficients } \\
\text { Beta }\end{array}$} & \multirow[b]{2}{*}{$t$} & \multirow[b]{2}{*}{ Sig. } \\
\hline & & $\mathrm{B}$ & Std. Error & & & \\
\hline \multirow[t]{2}{*}{1} & (Constant) & 3.949 & .045 & & 87.958 & .000 \\
\hline & Totalspendingpervisit & .001 & .000 & .128 & 4.261 & .000 \\
\hline \multirow[t]{3}{*}{2} & (Constant) & 3.883 & .048 & & 80.402 & .000 \\
\hline & Totalspendingpervisit & .001 & .000 & .115 & 3.847 & .000 \\
\hline & Totalvisitstorestaurants & .006 & .002 & .109 & 3.631 & .000 \\
\hline
\end{tabular}

Figure 4. Stepwise regression results

We can see from Figure 4 that only the two previously-significant variables entered the stepwise regression model - each section indicates that there were two "steps," and that each one was to enter a variable, and that no other variables were entered. The final model of an R-square of 0.028 and two significant predictors are the same: "Total spending per visit" and "Total visits to restaurants per month." By coincidence, each variable happens to have the same coefficient (rounded to three digits) in the stepwise-regression model as in the "enter [all variables]" multiple-regression model; without rounding, the coefficient would not be $100 \%$ identical, but are clearly very close to one another.

So, our "best model" (as defined by the stepwise-regression algorithm) to predict the value of a person's response to "I would visit a restaurant more often if a points-based loyalty program was present," our dependent variable (denoted "Y," with "Y $\mathrm{Y}_{\mathrm{c}}$ " representing the computed/predicted value) is:

$Y_{c}=3.949+.001 *($ Total spending per visit $)+.006 *($ Total visits to restaurants per month $)$.

To gain some understanding of the "leverage" of these variables, consider, for example, a person whose total spending per visit was $10 \%$ higher than average $(97.6 * 1.1=107.36$, the 97.6 coming from Figure 1), and whose total visits per month was $10 \%$ higher than average $(12.88 * 1.1=14.168$, again, the 12.88 coming from figure 1$)$. He/she would be predicted to have a score of

$$
\mathrm{Y}_{\mathrm{c}}=3.949+.001 *(97.6)+.006 *(12.88)
$$




$$
=3.949+.10736+.08501=\mathbf{4 . 2 4 1}
$$

This compares to the average value of the dependent variable of 4.09 (again, coming from Figure 1.) We did not incorporate gender directly into the regression analyses, but the earlier analysis shown in Figure 2 would suggest that a female would have a higher predicted value than a male.

\section{Limitations and Directions for Future Research}

Throughout this research, three specific limitations were identified. First, Loyalogy's survey results were limited to respondents in the United States, which (presumably) resulted in representative sample of the United States, but a non-representative sample of the global market of gamification.

Second, as we noted earlier, our analysis did not seek to identify and eliminate outliers. While we do not believe that our fundamental results would have changed, it is likely that the fit (manifested by the R-square value) of the multiple and stepwise regressions would have been somewhat higher, and that the coefficients would slightly change.

Third, only one form of gamification, loyalty programs, was analyzed throughout this study, resulting in a one-dimensional analysis of the effects of gamification on consumer loyalty.

Future researchers might expand this research by extending the analysis across multiple nations, in turn, producing a more global representation of the effects of gamification. We would also recommend that the outlier issue be considered. In addition, the analysis of other gamification platforms, not solely loyalty programs, would provide different perspectives on the relationship between consumer loyalty and gamification. Given the general deficit of quantitative research on gamification effects, there is great potential for future research within this field of study.

\section{References}

Conaway, R., \& Garay, M. (2014, November 4). Gamification and Service Marketing. Retrieved from http://www.ncbi.nlm.nih.gov/pmc/articles/PMC4227984/.

Egan, J. (2015, September 10). 8 statistics you need to know about gamification. Retrieved from http://www.ad-tech.com/ny/Page.cfm/action=Press/libID=1/libEntryID=44/listID=2.

Esteves, J. (2015, January 2). Imagineering 2015: Turn work into a game. Retrieved from http://articles.economictimes.indiatimes.com/2015-01-02/news/57611661_1_gamification-em ployee-engagement-jive.

Duffy, D. (2014, February 14). Loyalogy 2014 Restaurant Survey. Reward Programs Boosts visits $35 \%$. Retrieved from

http://loyalogy.com/2014/02/loyalogy-2014-consumer-study-restaurant-rewards-programs-bo ost-visits-35/

Hamari, J., Huotari, K., \& Tolvanen, J. (2014). Gamification and economics. In S. Walz \& S. 


\section{Macrothink}

Business and Economic Research

ISSN 2162-4860

2017, Vol. 7, No. 1

Deterding (Eds.), The Gameful World: Approaches, Issues, Applications. (pp. 139-162). Cambridge, MA: The MIT Press.

Hamari, J. (2013). Transforming homo economicus into homo ludens: a field experiment on gamification in a utilitarian peer-to-peer trading service. Electronic Commerce Research and Applications, 12, 236-245. https://doi.org/10.1016/j.elerap.2013.01.004

Investopedia.com (2016). What is a 'Loyalty Program'. Retrieved from http://www.investopedia.com/terms/l/loyalty-program.asp?lgl=no-infinite.

Moth, D. (2014, July 28). 10 Very Cool Examples of Experiential Marketing. Retrieved from https://econsultancy.com/blog/65230-10-very-cool-examples-of-experiential-marketing/.

Rouse, M. (2009, April). Transactional Marketing. Retrieved from http://searchcrm.techtarget.com/definition/transactional-marketing.

Seaborn, K. \& Fels, D. (2014). Gamification in theory and action: a survey. International Journal of Human-Computer Studies, 74, 14-31.

Tiwari, R. (2016, Feb. 16). Gamification Market Growing at 46.3\% CAGR to 2020 led by Social Media. Retrieved from

http://www.marketwatch.com/story/gamification-market-growing-at-463-cagr-to-2020-led-by -social-media-2016-02-16-5203147.

\section{Copyright Disclaimer}

Copyright for this article is retained by the author(s), with first publication rights granted to the journal.

This is an open-access article distributed under the terms and conditions of the Creative Commons Attribution license (http://creativecommons.org/licenses/by/3.0/). 